\title{
Extracorporeal membrane oxygenation in postcardiotomy patients: Factors influencing outcome
}

\author{
T. K. Susheel Kumar, MD, ${ }^{a}$ David Zurakowski, PhD, ${ }^{a}$ Heidi Dalton, MD, ${ }^{b}$ Sachin Talwar, MD, ${ }^{a}$ \\ Ayana Allard-Picou, ${ }^{a}$ Lennart F. Duebener, MD, ${ }^{a}$ Pranava Sinha, MD, ${ }^{a}$ and Achintya Moulick, MD, MBA ${ }^{a}$
}

Objective: Our objective was to assess the morbidity and mortality in children requiring extracorporeal membrane oxygenator support after cardiac surgery and to determine factors influencing outcome.

Methods: Between January 2003 and June 2008, 58 patients required extracorporeal membrane oxygenator sup-
port after cardiac surgery. A retrospective study was performed and factors influencing outcome were determined
by logistic regression modeling with the probability of outcome based on a combination of multivariate predictors.

Results: Median age and weight were 12 days and $3.3 \mathrm{~kg}$, respectively. Thirty-one patients had single ventricle repair and 27 had biventricular repair. Median duration of support with the oxygenator was 6 days. Thirty-nine $(67 \%)$ patients were successfully weaned off the support, but only $24(41 \%)$ survived to hospital discharge. Chief complications were renal failure (31\%), neurologic complications (29\%), and sepsis (16\%). Multivariable logistic regression analysis identified 10 days or more of extracorporeal membrane oxygenation (odds ratio $=6.1$ ), urine output less than $2 \mathrm{~mL} \cdot \mathrm{kg}^{-1} \cdot \mathrm{h}^{-1}$ in first 24 hours (odds ratio $=15$ ), renal failure (odds ratio $=9.4$ ), and $\mathrm{pH}$ less than 7.35 after 24 hours of extracorporeal membrane oxygenation (odds ratio $=82$ ) as significant independent factors associated with failure to wean off extracorporeal membrane oxygenation. Factors associated with failure of hospital discharge despite successful decannulation were as follows: extracorporeal membrane oxygenator support time of 10 days or more, red blood cell transfusion of greater than $1000 \mathrm{~mL} / \mathrm{kg}$ during the entire period of oxygenator support, and sepsis. Patients with single ventricle repair were at higher risk of hospital mortality.

Conclusion: Longer duration of extracorporeal membrane oxygenator support, low $\mathrm{pH}$ and urine output in the first 24 hours, and renal failure are significant factors associated with mortality during extracorporeal membrane oxygenator support. Exposure to high amounts of blood transfusion during extracorporeal oxygenation, extended extracorporeal membrane oxygenator support, and sepsis increase risk of death after successful decannulation. (J Thorac Cardiovasc Surg 2010;140:330-6)

Supplemental material is available online.

Earn CME credits at

http://cme.ctsnetjournals.org

Since its inception, the use of extracorporeal membrane oxygenation (ECMO) after cardiopulmonary bypass (CPB) for correction of congenital heart defects (CHDs) has continued to steadily increase. However, the average survivals have remained essentially constant between $35 \%$ and $45 \%{ }^{1}$ with a significant rate of complications. ${ }^{1}$ Despite

From the Departments of Cardiovascular Surgery ${ }^{\mathrm{a}}$ and Critical Care, ${ }^{\mathrm{b}}$ Children's National Medical Center, Washington, DC.

Disclosures: None.

Received for publication Aug 14, 2009; revisions received Jan 17, 2010; accepted for publication Feb 13, 2010.

Address for reprints: Achintya Moulick, MD, MBA, Chief Cardiothoracic Surgery, St. Christopher's Hospital for Children, 3601 A St, Philadelphia, PA 19134 (E-mail: achintya1.moulick@tenethealth.com).

0022-5223/\$36.00

Copyright (C) 2010 Published by Elsevier Inc. on behalf of The American Association for Thoracic Surgery

doi:10.1016/j.jtcvs.2010.02.034 attempts to identify factors affecting outcome, ${ }^{2-8}$ there is no unanimous opinion. The purpose of this study was to determine factors influencing mortality and morbidity in patients placed on ECMO after CPB.

\section{PATIENTS AND METHODS \\ Study Population}

Between January 2003 and June 2008, 58 consecutive patients requiring ECMO after repair of CHDs were retrospectively studied. These 58 patients represented $4.5 \%$ of 1261 cardiac procedures for correction of CHDs at the Children's National Medical Center, Washington, DC. The study period involved a number of surgeons and was a stage of transition not only in terms of operative techniques but also in having an in-house senior fellow available for cannulation around the clock starting from August 2007. This study was approved by our institutional review board.

Data were collected from detailed patient charts available in the medical records department, the ECMO department, and the blood bank. We included all patients who required ECMO after cardiac surgery during the index admission regardless of duration from surgery. Four patients had additional ECMO runs during the same admission. They were counted only once and information from the initial operation and first ECMO run was analyzed. Multiple factors (clinical and biochemical) were analyzed for their impact on survival and morbidity. These factors included those that have been analyzed in previous studies ${ }^{2-8}$ and some that we hypothesized could affect outcome (Table 1 and Table E1).

Inotrope score (Table E2) was calculated using this formula: inotrope score $=$ dopamine + dobutamine + epinephrine + norepinephrine + (milrinone $\times 15$ ), all in micrograms per kilogram per minute times 100 . $^{7}$ 


\section{Abbreviations and Acronyms \\ CHD = congenital heart defects \\ $\mathrm{CPB}=$ cardiopulmonary bypass \\ $\mathrm{CPR}=$ cardiopulmonary resuscitation \\ $\mathrm{ECMO}=$ extracorporeal membrane oxygenation \\ PRBCs $=$ packed red blood cells}

\section{Site of Cannulation}

Patients who required ECMO in the operating room owing to failure to wean from $\mathrm{CPB}$ were cannulated through the right atrium and the ascending aorta.

A transthoracic route was also generally used for patients requiring emergency ECMO in the intensive care unit in the immediate postoperative period $(<15$ days), whereas peripheral cannulation was used for those in the later period. The neck vessels were used in patients weighing less than $15 \mathrm{~kg}$; otherwise, the femoral vessels were used. The final decision for the site of cannulation was left to the discretion of the surgeon.

A standard ECMO circuit consisting of a roller pump head (Jostra; Maquet Inc, Rastatt, Germany) and a membrane oxygenator (Medtronic, Inc, Minneapolis, Minn) was used. Monitors for pressure before and after ECMO were used. A disposable heat exchanger was used to maintain constant temperature of the blood in the circuit. The priming volume of the circuit depended on the surface area of the oxygenator and the patient weight. In an emergency situation, a rapid ECMO circuit consisting of a hollow fiber oxygenator (Minimax/Affinity; Medtronic, Inc) with a centrifugal pump head (Bio-Medicus; Medtronic, Inc) was used for quick priming and ease of deployment. The rapid ECMO circuit was primed with crystalloid unless blood was immediately available. The circuit required an average priming volume of $250 \mathrm{~mL}$ for an infant. Once the patient was deployed on ECMO, packed red blood cells (PRBCs) were transfused and the excess crystalloid removed by a manual exchange transfusion method. This circuit was replaced within 72 hours with a conventional circuit consisting of a silicone membrane oxygenator as described above unless the ECMO support was no longer required. The conventional circuit had a larger priming volume of approximately $500 \mathrm{~mL}$ but did not require change unless there were clots within the system. Every change of circuit thus exposed the patient to an additional $500 \mathrm{~mL}$ of blood in addition to a new surface lining of tubings and oxygenator. Whenever elective ECMO was used in the operating room, separation from CPB and reversal of heparinization were attempted before institution of ECMO to reduce bleeding. A hematocrit value of greater than $35 \%$ was maintained on ECMO with transfusion to a hematocrit value of $45 \%$ before discontinuing ECMO, especially in cyanotic patients.

ECMO flows were regulated on the basis of patient variables such as systemic blood pressure, organ perfusion, venous saturations, and serial lactate measures. When on full flow rates, inotropic support was kept at a minimum, although most patients continued to receive milrinone throughout their ECMO course. Vasoactive support was often increased as weaning commenced and the cardiac load was increased. Similarly, at full flows, the ventilatory support was minimized and was gradually increased as the ECMO support was weaned off. The gas flow rate and blender were adjusted on the ECMO circuit to keep the blood gas values within the normal range. Fluid input to the patient was adjusted according to the body weight and other clinical factors like temperature and fluid losses. Ultrafiltration was performed with a hemofilter (Minntech HPH 400; Minntech, Minneapolis, Minn) in line with the ECMO circuit to augment fluid removal in cases of volume overload. Hemodialysis was used in patients with renal insufficiency or renal failure. Continuous heparin was infused to maintain activated clotting time between 180 and 200 seconds except when there was excessive bleeding and a lower activated clotting time was accepted. Platelet count was maintained above $100,000 / \mathrm{mL}$. Daily measurement of prothrombin time, partial thromboplasin time, and fibrinogens was also performed. Fresh frozen plasma was administered to maintain normal prothrombin time and fibrinogen levels and partial thromboplastin time less than 150 seconds.

For patients with single ventricle repair and systemic-to-pulmonary shunts, we routinely undersized the shunt by applying surgical clips to reduce the steal of blood from the systemic circulation instead of increasing the ECMO flows, a strategy used by other groups. ${ }^{2,9}$ We empirically clipped the shunt to $50 \%$ of diameter at the time of ECMO deployment, and further clipping was based on perfusion pressure. These clips were later removed as the patient was weaned off the ECMO support. A left atrial vent was used in patients with biventricular repair when there was evidence of poor decompression of the left side of the heart. Carotid reconstruction was always attempted in all cases of neck cannulation.

Renal failure was defined as oliguria or anuria with raised creatinine level $(>1.5 \mathrm{mg} / 100 \mathrm{dL})$ (Table E2). Neurologic complication was defined as intracranial infarct or hemorrhage, evidence of hypoxic insult, or brain death. Head ultrasound was used to define intracranial infarct or hemorrhage, whereas brain death was diagnosed as per the standard accepted criteria. Head ultrasound was performed every day for the first 3 days and every alternate day or as indicated after that. The use of computed tomographic scan (portable) and electroencephalography were based on clinical condition and suspicion of neurologic damage. Sepsis was defined as systemic inflammatory response in the presence of infection (suspected or proven) (International Pediatric Sepsis Consensus Conference, 2005). Patients in whom severe neurologic damage developed or in whom recovery was deemed futile by the care team (in consultation with the family) were electively removed from ECMO support.

\section{Statistical Analysis}

Continuous variables are expressed as median and interquartile range owing to skewness. Kaplan-Meier survival analysis was used to compare patient outcome on ECMO between subgroups such as $\mathrm{pH}$ of 7.35 or more versus $\mathrm{pH}$ less than 7.35 at 24 hours with survival curves compared by the log-rank test and $95 \%$ confidence intervals constructed by the Greenwood formula. ${ }^{10}$ Cutoff values chosen were determined in part on the basis of medians for the entire cohort of 58 patients; however, we did also review univariate receiver operating characteristic curves and determined an optimal cutoff value for $\mathrm{pH}$, urine output, and ECMO duration using the Youden index to maximize sensitivity. Factors associated with death on ECMO and hospital mortality were evaluated by univariate analysis on the basis of clinically appropriate cutoff values using logistic regression analysis and tested by multivariate analysis using a stepwise logistic model. ${ }^{11}$ Odds ratios and $95 \%$ confidence intervals were calculated for significant factors, and probability of death on $\operatorname{ECMO}(\mathrm{n}=19)$ and hospital mortality $(\mathrm{n}=34)$ were derived for combinations of multivariate factors to provide clinical prediction rules. We limited the number of covariates in the multivariate data analyses with the rationale of obtaining a more numerically stable model and a set of prognostic variables that is more easily generalized and less dependent on the observed data. ${ }^{12,13}$ To validate the predictive ability of the fitted multivariable models, we used the c-index to measure how well our logistic regression models predicted outcome, with a greater $\mathrm{c}$ value (maximum $1, \mathrm{c}=0.5$ indicating a model with no discrimination) indicating a greater ability of the model to predict the outcome, where typically 0.80 or higher reflects excellent predictive ability. ${ }^{11}$ Statistical analyses were performed with the SPSS for Windows software system (version 17.0; SPSS, Inc, Chicago, Ill).

\section{RESULTS}

Characteristics for the entire cohort of 58 patients (31 boys, 27 girls) are summarized in Table 1. Median age and weight were 12 days and $3.3 \mathrm{~kg}$, respectively. The 
TABLE 1. Characteristics of children undergoing ECMO in study cohort $(\mathbf{n}=\mathbf{5 8})$

\begin{tabular}{|c|c|c|}
\hline Variable & $\begin{array}{l}\text { Median value or } \\
\text { No. of patients }\end{array}$ & $\begin{array}{c}\text { Interquartile } \\
\text { range or } \%\end{array}$ \\
\hline Age at surgery, $d$ & 12 & $4-204$ \\
\hline Weight, kg & 3.3 & $2.6-6.2$ \\
\hline \multicolumn{3}{|l|}{ Gender } \\
\hline Male & 31 & 53 \\
\hline Female & 27 & 47 \\
\hline \multicolumn{3}{|l|}{ Race } \\
\hline White & 21 & 36 \\
\hline African American & 26 & 45 \\
\hline Hispanic & 9 & 16 \\
\hline Asian & 2 & 3 \\
\hline \multicolumn{3}{|l|}{ Diagnosis } \\
\hline L-R shunt & 4 & 7 \\
\hline Left-sided obstruction & 3 & 5 \\
\hline HLHS & 20 & 34 \\
\hline Cyanotic, increased PBF & 5 & 9 \\
\hline Cyanotic, decreased PBF & 15 & 26 \\
\hline $\begin{array}{l}\text { Cyanotic, increased pulmonary } \\
\text { congestion }\end{array}$ & 8 & 14 \\
\hline Other & 3 & 5 \\
\hline \multicolumn{3}{|l|}{ Intraoperative features } \\
\hline $\mathrm{CPB}$ time, $\min$ & 118 & $85-188$ \\
\hline Crossclamp time, $\min$ & 48 & $40-65$ \\
\hline DHCA, min & 28 & $0-50$ \\
\hline \multicolumn{3}{|l|}{ Laboratory values, pre-ECMO } \\
\hline $\mathrm{pH}$ level & 7.29 & $7.19-7.42$ \\
\hline Serum bicarbonate, $\mathrm{mEq} / \mathrm{L}$ & 24.5 & $17.2-27.9$ \\
\hline $\begin{array}{l}\text { Lactate } 1(\mathrm{mmol} / \mathrm{L} 4-12 \mathrm{~h} \\
\text { pre-ECMO) }\end{array}$ & 4.1 & $2.8-7.8$ \\
\hline $\begin{array}{l}\text { Lactate } 2(\mathrm{mmol} / \mathrm{L} 0-4 \mathrm{~h} \\
\text { pre-ECMO) }\end{array}$ & 7.6 & $3.4-11.2$ \\
\hline Inotrope score-start of ECMO & 1050 & $762-1488$ \\
\hline \multicolumn{3}{|l|}{ Indication for ECMO } \\
\hline Cardiac arrest & 29 & 50 \\
\hline Failure to wean from bypass & 19 & 33 \\
\hline Low cardiac output & 8 & 14 \\
\hline Hypoxia & 2 & 3 \\
\hline ECMO duration, $\mathrm{d}$ & 6 & $3-10$ \\
\hline \multicolumn{3}{|l|}{ Laboratory values at $24 \mathrm{~h}$} \\
\hline $\mathrm{pH}$ level & 7.44 & $7.36-7.50$ \\
\hline Lactate, $\mathrm{mmol} / \mathrm{L}$ & 2.2 & $1.80-3.80$ \\
\hline Serum bicarbonate, $\mathrm{mEq} / \mathrm{L}$ & 30.0 & 27.0-34.4 \\
\hline $\begin{array}{l}\text { Urine output, } \mathrm{mL} \cdot \mathrm{kg}^{-1} \cdot \mathrm{h} \text { first } \\
\qquad 24 \mathrm{~h}^{-1}\end{array}$ & 3.30 & $1.85-6.95$ \\
\hline PRBCs, during support, $\mathrm{mL} / \mathrm{kg}$ & 715 & $440-1117$ \\
\hline
\end{tabular}

$E C M O$, Extracorporeal membrane oxygenation; $L-R$, left-to-right; $H L H S$, hypoplastic left heart syndrome; $P B F$, pulmonary blood flow; $C P B$, cardiopulmonary bypass; $D H C A$, deep hypothermic circulatory arrest; $P R B C s$, packed red blood cells.

children requiring mechanical support represented a wide variety of cardiac lesions. Single ventricle repair was performed in 53\%. The major indication for ECMO was cardiac arrest. Among 58 patients, $19(33 \%)$ died on ECMO. A total of $34(59 \%)$ patients died in the hospital. A total of $18(31 \%)$ patients had renal failure and $17(29 \%)$ had

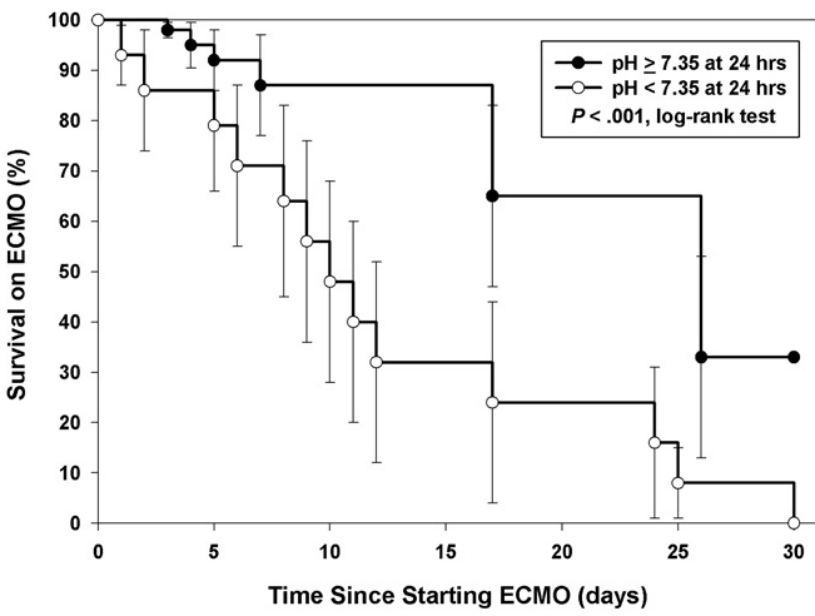

FIGURE 1. Kaplan-Meier survival curves for patients with $\mathrm{pH} \geq 7.35$ and those $<7.35$ at 24 hours. The error bars denote $95 \%$ confidence intervals as determined by the Greenwood formula.

neurologic complications. Intracranial hemorrhage occurred in 15 patients; cerebral infarction in 5; and clinical seizures in 3. Nine $(16 \%)$ patients had sepsis. Although abnormal bleeding parameters occurred in many patients, true disseminated intravascular coagulopathy (defined as abnormal prothrombin time, partial thromboplastin time, fibrinogen, and low platelets) occurred in only 2 patients and could be ultimately controlled with blood products. Four patients required second ECMO runs. Three of them survived the second run, too, but died of sepsis, whereas in the fourth patient, features of multiorgan failure developed on the second ECMO run and support was discontinued. These 4 patients were counted among those who survived ECMO but died before hospital discharge. For purposes of data analysis, information from only the first ECMO run was used. Complications during the entire hospital course were included.

We performed 3 sets of univariate and multivariate analyses to identify prognostic factors that differentiate (1) survivors from nonsurvivors on ECMO, (2) overall survivors from patients who died in the hospital, and (3) survivors versus nonsurvivors among children who were weaned from ECMO.

Seven significant factors associated with death on ECMO were identified by univariate analysis. Mean $\mathrm{pH}$ levels at 24 hours for survivors and nonsurvivors of ECMO were 7.48 and 7.31, respectively (Figure E1). Median survival time in patients with a $\mathrm{pH}$ of 7.35 or more was 27 days versus only 10 days in patients with a pH less than 7.35 (Figure 1).

Four of the 7 variables associated with failure to wean from ECMO were confirmed as independent factors by multivariable logistic regression analysis (Table 2). In the next set of analyses, we identified 9 factors associated with hospital mortality by univariate analysis. Of these 9,5 were confirmed as independent risk factors by multivariate logistic regression analysis, including single ventricle physiology, 
TABLE 2. Factors associated with patient mortality

Factors associated with patient mortality on ECMO

\begin{tabular}{|c|c|c|c|c|}
\hline Variable & Survived ECMO $(n=39)$ & Died on ECMO $(n=19)$ & Odds ratio $(95 \% \mathrm{CI})$ & Multivariate $P$ value \\
\hline \multicolumn{5}{|l|}{ ECMO time $\geq 10 \mathrm{~d}$} \\
\hline Yes & $6(37)$ & $10(63)$ & $6.1(1.8-21.4)$ & .005 \\
\hline No & $33(79)$ & $9(21)$ & & \\
\hline \multicolumn{5}{|l|}{$\mathrm{pH}<7.35$} \\
\hline Yes & $1(7)$ & $13(93)$ & $82.3(9.0-750)$ & $<.001$ \\
\hline No & $38(86)$ & $6(14)$ & & \\
\hline \multicolumn{5}{|c|}{ Urine $<2 \mathrm{~mL} \cdot \mathrm{kg}^{-1} \cdot \mathrm{h}$} \\
\hline Yes & $4(25)$ & $12(75)$ & $15.0(3.7-60)$ & .012 \\
\hline No & $35(83)$ & $7(17)$ & & \\
\hline \multicolumn{5}{|l|}{ Renal failure } \\
\hline Yes & $6(33)$ & $12(67)$ & $9.4(2.7-33.7)$ & $<.001$ \\
\hline No & $33(83)$ & $7(17)$ & & \\
\hline \multicolumn{5}{|c|}{ Factors associated with hospital mortality } \\
\hline Variable & Survivors $(n=24)$ & Nonsurvivors $(n=34)$ & Odds ratio $(95 \% \mathrm{CI})$ & Multivariate $P$ value \\
\hline \multicolumn{5}{|l|}{ Surgical repair } \\
\hline Single ventricle & $8(26)$ & $23(74)$ & $4.9(1.6-14.8)$ & .007 \\
\hline Biventricular & $16(59)$ & $11(41)$ & & \\
\hline \multicolumn{5}{|l|}{ ECMO time $\geq 10, d$} \\
\hline Yes & $1(6)$ & $15(94)$ & $18.2(2.3-150)$ & $<.001$ \\
\hline No & $23(55)$ & $19(45)$ & & \\
\hline \multicolumn{5}{|l|}{ Lactate $>4 \mathrm{mmol} / \mathrm{L}$} \\
\hline Yes & $1(7)$ & $13(93)$ & $14.2(2.0-118)$ & $<.001$ \\
\hline No & $23(52)$ & $21(48)$ & & \\
\hline \multicolumn{5}{|l|}{ Sepsis } \\
\hline Yes & $0(0)$ & $9(100)$ & ND & $<.001$ \\
\hline No & $24(49)$ & $25(51)$ & & \\
\hline \multicolumn{5}{|l|}{ Renal failure } \\
\hline Yes & $2(11)$ & $16(89)$ & $9.8(2.0-48.3)$ & .008 \\
\hline No & $22(55)$ & $18(45)$ & & \\
\hline \multicolumn{5}{|c|}{ Factors associated with mortality for subgroup of patients weaned from ECMO } \\
\hline Variable & Survivors $(n=24)$ & Nonsurvivors $(\mathbf{n}=15)$ & Odds ratio $(95 \% \mathrm{CI})$ & Multivariate $P$ value \\
\hline \multicolumn{5}{|l|}{ ECMO time $\geq 10 \mathrm{~d}$} \\
\hline Yes & $1(17)$ & $5(83)$ & $11.5(1.5-112)$ & .02 \\
\hline No & $23(70)$ & $10(30)$ & & \\
\hline \multicolumn{5}{|c|}{ PRBCs > $1000 \mathrm{~mL} / \mathrm{kg}$} \\
\hline Yes & $1(17)$ & $5(83)$ & $11.5(1.5-112)$ & .02 \\
\hline No & $23(70)$ & $10(30)$ & & \\
\hline \multicolumn{5}{|l|}{ Sepsis } \\
\hline Yes & $0(0)$ & $6(100)$ & ND & $<.001$ \\
\hline No & $24(73)$ & $9(27)$ & & \\
\hline
\end{tabular}

Percentages are calculated horizontally and shown in parentheses. $P$ values are based on the likelihood ratio test from logistic regression analysis. $\mathrm{pH}$, lactate, and urine output were measured at 24 hours. ECMO, Extracorporeal membrane oxygenation; $C I$, confidence interval; PRBCs, packed red blood cells; $N D$, not determinable because all 9 patients with sepsis died. Odds ratios and CIs for each factor were estimated from the multivariable analysis.

ECMO time, lactate, sepsis, and renal failure (Table 2). We constructed probability curves illustrating the relationship between time in days on ECMO and the probability of hospital mortality for patients with and without renal failure (Figure E2) and single ventricle versus biventricular repair (Figure E3 and Table E3).

In the subgroup of 39 patients weaned from ECMO, 3 independent factors associated with hospital mortality were identified (ECMO time, amount of PRBCs, and sepsis)
(Table 2). Sepsis was not included in the multivariable model because all patients with sepsis died and hence it perfectly predicts mortality. However, it is considered a significant factor associated with mortality $(P<.001)$.

In as much as the amount of blood transfused was confirmed as a multivariate risk factor, we derived the probability of hospital mortality as a function of PRBCs transfused (Figure 2) as a continuous variable adjusted for body weight $(P<.01)$ and illustrate this relationship. 


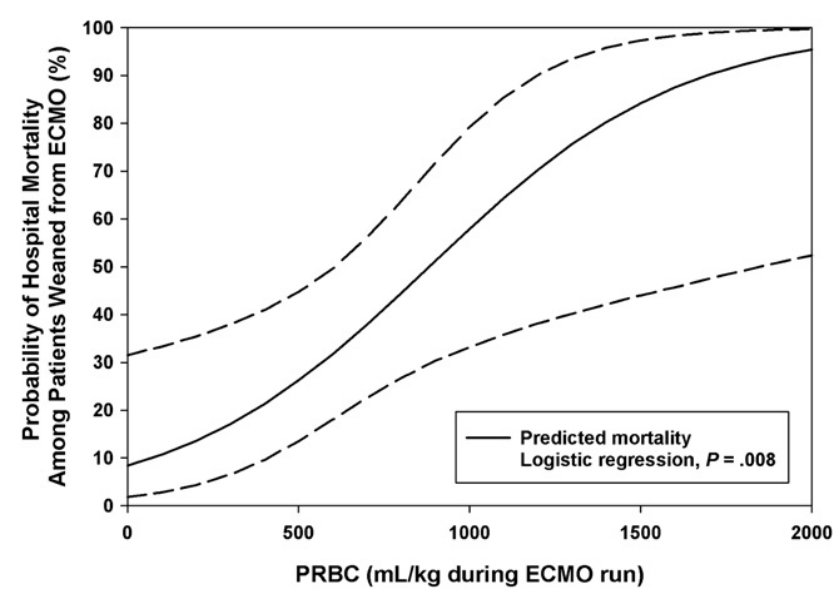

FIGURE 2. Theoretical curve (solid) shows the increasing risk of hospital mortality with greater blood transfusion $(P<.01)$ among patients weaned from ECMO. The $95 \%$ confidence interval obtained by the logistic regression model is rather broad (dashed), although clearly indicates higher risk of death with greater amounts of blood transfused. ECMO, Extracorporeal membrane oxygenation; $P R B C$, packed red blood cells.

Results of computing the c-index for assessing the concordance between the predicted outcomes based on our fitted multivariable models and the observed outcomes revealed very strong ability of the models to predict outcome. Referring to the 3 multivariable models summarized in Table 2, the c-index value equals 0.981 for predicting mortality on ECMO based on the 4 significant independent risk factors, and the c-index value equals 0.958 for hospital mortality based on 5 risk factors (both analyses are based on all 58 patients). In addition, the last multivariable model presented in Table 2, showing the 3 significant risk factors for predicting failure to be discharged among the 39 patients who were weaned from ECMO, had a c-index of 0.881, again indicating excellent predictive ability of the model to predict this outcome.

During this period, a total of 19 patients who underwent stage 1 Norwood for hypoplastic left heart syndrome were placed on ECMO. Of these, 5 patients had a Blalock-Taussig shunt and 14 patients had the Sano modification. Of the 5 patients who underwent a Norwood procedure with the Blalock-Taussig shunt, 4 could not be weaned off ECMO and only 1 patient survived to discharge. Of the 14 patients who underwent Norwood with Sano modification, 11 could be weaned off ECMO. However, of these 11, only 2 patients survived to hospital discharge. Nevertheless, the Sano shunt has the important advantage during ECMO that it does not steal from the perfusion flow and there is no need for clamping or constriction.

Male gender, site of cannulation (neck), low first 24-hour urine output, and higher amount of blood transfusion were significant factors associated with renal failure. In terms of days from surgery to ECMO, there was a difference between patients who underwent chest cannulation (median, 1 day; range, $0-17$ days) and those who underwent neck cannulation ( $\mathrm{n}=10$; median, 12 days; range, $0-65$ days; $P<.001$ ). Five of the 10 neck cannulations were done beyond 15 days; 2 of them after Norwood, 2 after repair of total anomalous pulmonary venous return, and 1 after repair of ventricular septal defect and coarctation in a patient with borderline left ventricular function.

Among the 17 (29\%) patients who had neurologic complications, the only significant associated factor was a high lactate level at 24 hours $(P=.03)$. Seven $(50 \%)$ of the 14 patients with lactate levels greater than $4 \mathrm{mmol} / \mathrm{L}$ had neurologic complications, whereas $10(23 \%)$ of the 44 of patients with lactate levels less than $4 \mathrm{mmol} / \mathrm{L}$ had neurologic complications. In the subgroup of 29 patients who required ECMO for cardiac arrest in our study, the duration of cardiopulmonary resuscitation (CPR) was not a risk factor for neurologic complications.

On analyzing the risk factors for sepsis, we found that the only significant factor was mediastinal re-exploration. Whereas $7(27 \%)$ of the 26 patients with re-explorations had sepsis, only $2(6 \%)$ of the 32 without any reexplorations had sepsis $(P=.02)$.

Half of our patients required ECMO for refractory cardiac arrest. Among them, the 17 nonsurvivors had higher CPR time (51 \pm 10 minutes) than did the 12 survivors $(42 \pm 8$ minutes; $P=.019$ ).

\section{DISCUSSION}

Ever since Baffes and associates ${ }^{14}$ first reported the use of ECMO after palliative repair of CHD in 1970, it has been widely used for resuscitation after cardiac operations in children. However, there are no widely established criteria governing its use, partly because of inconsistency of results, ${ }^{2-9}$ which reflects differences in institutional policy and spectrum of surgical procedures. Our policy is to use ECMO as a resuscitative tool for both single and biventricular repair. This provided us an ideal platform to test the various factors. Although almost all studies of ECMO list risk factors for hospital mortality, ${ }^{2-8}$ we went further by analyzing risk factors for death on ECMO and subsequent mortality after decannulation separately. This has obvious clinical implications.

Consistent with previous studies, ${ }^{2,5,7,8}$ ECMO duration was a strong determinant not only of death on ECMO but also after weaning from ECMO. Longer duration of extracorporeal bypass has widespread deleterious influence on the organ systems, including the immune system, ${ }^{15-17}$ which may contribute to later mortality. Most of our patients who died after weaning from ECMO died of sepsis or multiorgan dysfunction. New strategies to reduce the inflammatory effects of ECMO may reduce these problems. ${ }^{18,19}$ Albumin and heparin-coated circuits (" biopacification") have been proven to reduce the overall inflammatory effects by reducing the blood-surface interaction. ${ }^{20}$ 
Levels of $\mathrm{pH}$ and lactate, both markers of tissue perfusion, have been analyzed as indicators of outcome. ${ }^{6}$ Similar to the Boston study, ${ }^{4} \mathrm{pH}$ after 24 hours of ECMO deployment was predictive of death on ECMO. On the other hand, a lactate level at 24 hours was more predictive of overall hospital mortality. In their study, Kolovos and associates ${ }^{6}$ reported that lactate levels at 48 hours were more predictive of a worse outcome than at 24 hours. Inasmuch as blood flow to the organs is restored by institution of ECMO, abnormal values of these indicators of tissue perfusion reflect either the overall hypoperfusion before deployment of ECMO or problems in oxygen delivery and extraction after deployment of ECMO. The lactate levels before deployment of ECMO did not seem to prognosticate the outcome in our study.

Urine output in the first 24 hours of the ECMO run, a surrogate marker of organ perfusion, was an independent factor influencing death on ECMO. This finding is similar to the experience of the Boston group. ${ }^{4}$ Again, a low urine output in the first 24 hours reflects either the ischemic insult to the kidneys sustained during the pre-ECMO period or continued organ perfusion abnormalities despite extracorporeal support.

Renal failure was significantly associated with death on ECMO, and two thirds of the patients in whom renal failure developed while supported by ECMO died. Renal failure was also predictive of overall hospital mortality. In our study, 16 of the 18 patients who had renal failure died before discharge despite the use of hemodialysis in all patients with renal failure. Renal malfunction has been shown to have an adverse influence on the various organ systems and significantly decreases chances of recovery. ${ }^{2-7} \mathrm{We}$ found that male gender, neck cannulation, low first 24-hour urine output, and higher amount of blood transfusion were significant factors associated with renal failure. Although we were unable to explain male gender as a risk factor, patients who underwent neck cannulation probably had a longer period of hypoperfusion (low cardiac output) as they were farther out from surgical correction. We did not find significant difference in duration of CPR between the 2 groups. A low 24-hour urine output was predictive of eventual renal failure and may reflect a greater period of blood flow compromise to the kidneys occurring either before or after placement on ECMO. The relation between blood transfusion and endorgan damage including kidneys is widely established. ${ }^{21}$

Similar to previous studies, ${ }^{6,7}$ biventricular repair was associated with a better survival after ECMO.

Neurologic complications were not an independent indicator of mortality, although they represented a source of great morbidity. The only significant risk factor was a high lactate level at 24 hours $(P=.03)$. The duration of CPR was not a risk factor for neurologic complications. Interestingly, a recent study by the Western Canadian Complex Pediatric Therapies Program Follow-up Group ${ }^{22}$ showed that the time for lactate to normalize on ECMO was a risk factor for poor mental score at 2 years' follow up. Moreover, they could not find any association between CPR duration and mental score at follow-up. Although both of these were long-term findings compared with the short-term in-hospital neurologic outcomes reported here, the concurrence of indicators of neurologic outcome, that is, lactate level and duration of CPR, is a significant finding that requires further validation in larger patient series. The incidence of neurologic complications was independent of the site of cannulation in our analysis, which is similar to other experiences. $^{4}$

Sepsis has been shown to have a negative outcome on patients treated with ECMO in the past. ${ }^{23}$ Sepsis is generally a later complication, especially in patients on prolonged ECMO support. Hence it is not surprising that it was a better predictor of mortality after successful weaning from ECMO. In our study, no patient in whom sepsis developed survived to hospital discharge. Mediastinal re-exploration was the only risk factor for sepsis. A greater amount of PRBC transfusion during the ECMO run had a definite negative effect on the patient survival despite the fact that the patient was able to be weaned from ECMO support. Recent studies have linked bleeding and hence exposure to increased blood volume as a risk factor for hospital mortality after ECMO. ${ }^{5}$ Blood transfusion has been shown to be associated with increased incidence of infections. ${ }^{24}$ It is not surprising that most of the later deaths were due to sepsis, which could be directly related to the detrimental effects of ECMO ${ }^{15-17}$ and blood on the immune system. The strategy of rapid ECMO circuit followed by a conventional circuit, often more than once, exposed the patient to a staggering amount of blood volume. This is in addition to any blood replacement that the patient received for bleeding because of either surgical causes or coagulopathy. One should also not discount the hemolysis that occurs especially with the centrifugal pump. Better ECMO circuit designs that do not require change, reversal of heparinization even for a short time before deployment of ECMO, meticulous surgical hemostasis, and cell salvage can all help reduce the amount of blood exposure. Of late, we have started using the Quadrox oxygenator (Jostra; Maquet). This is a polymethylpentene hollow fiber oxygenator that has a smaller priming volume and is also long-lasting, unlike the previous hollow fiber membrane oxygenator. Thus, once used on the rapid ECMO circuit, it does not require a change; hence exposure to blood is much less. It is hoped that miniaturization of ECMO circuits ${ }^{25}$ in the future will reduce not only the priming volume but also blood contact with artificial surfaces.

The anatomic diagnosis or indication for ECMO, including cardiac arrest, did not make any difference in the survival in our study. Half of our patients required ECMO for refractory cardiac arrest. The duration of CPR made a difference in overall survival within this group, although it did not affect neurologic outcome. Inotrope score has been evaluated in the past as a predictor of outcome. We did not find any 
statistically useful relation between inotrope score at ECMO initiation and the outcome. This is similar to other studies. ${ }^{2,7}$

\section{Study Limitations}

In our study, hemodynamic variables, ventilatory parameters, or arrhythmias on ECMO were not analyzed. Despite the good predictive performance of our multivariable models, we agree that the $95 \%$ confidence intervals are wide, owing to rather small sample size. Despite our efforts to conduct rigorous statistical analysis to determine predictors of outcome, the nature of the study is retrospective and this raises potential issues regarding possible confounding or bias, which are concerns for all retrospective cohort studies. A major limitation of such a retrospective cohort design is that collection of variables is not under the control of investigator and therefore variables that could have had an important influence on outcome may not be available for analysis. We also did not analyze outcomes after hospital discharge, including long-term mortality or possible neurologic complications. ${ }^{22}$ Finally, this report details patient outcome from a single center. Inasmuch as centers may have varying surgical approaches and ECMO management protocols, it is difficult to generalize these findings without further evaluation of large numbers of patients in a multicenter fashion.

\section{CONCLUSION}

Although ECMO provides effective mechanical support after cardiac operations in children, mortality and complication rates are high. Its use must be tempered with the recognition of factors that predict poor outcome. This is all the more important with rising medical care costs and the heavy resource use that ECMO currently entails. Prolonged duration of ECMO support, renal failure, and markers of poor tissue perfusion at the end of first 24 hours of support are factors influencing mortality on ECMO. Patients who have undergone single ventricle repair are at increased risk of hospital mortality. Exposure to high amounts of blood transfusion while on ECMO, long duration of ECMO support, and sepsis all increase the risk of death in patients even after successful decannulation. Better strategies are needed for improving patient outcomes.

We thank the surgeons who contributed to this study, including Frank Midgeley, MD, Gregory DiRusso, MD, David M. McMullan, MD, Bassem Mora, MD, Luca Vricella, MD, and Richard A. Jonas, MD. We also thank members of the ECMO and blood bank services, who helped immensely with data collection.

\section{References}

1. ECLS Registry Report. International summary, Jan 2009. Extracorporeal life support organization. Ann Arbor (MI).

2. Aharon AS, Drinkwater DC Jr, Churchwell KB, Quisling SV, Reddy VS, Taylor M, et al. Extracorporeal membrane oxygenation in children after repair of congenital cardiac lesions. Ann Thorac Surg. 2001;72:2095-101.
3. Morris MC, Ittenbach RF, Godinez RI, Portnoy JD, Tabbutt S, Hanna BD, et al. Risk factors for mortality in 137 pediatric cardiac intensive care unit patients managed with extracorporeal membrane oxygenation. Crit Care Med. 2004;32: 1061-9.

4. Duncan BW, Hraska V, Jonas RA, Wessel DL, Del Nido PJ, Laussen PC, et al. Mechanical circulatory support in children with cardiac disease. J Thorac Cardiovasc Surg. 1999;117:529-42.

5. Balasubramanian SK, Tiruvoipati R, Amin M, Aabideen KK, Peek GJ, Sosnowski AW, et al. Factors influencing the outcome of paediatric cardiac surgical patients during extracorporeal circulatory support. J Cardiothorac Surg. 2007;2:4.

6. Kolovos NS, Bratton SL, Moler FW, Bove EL, Ohye RG, Bartlett RH, et al. Outcome of pediatric patients treated with extracorporeal life support after cardiac surgery. Ann Thorac Surg. 2003;76:1435-41.

7. Baslaim G, Bashore J, Al-Malki F, Jamjoom A. Can the outcome of pediatric extracorporeal membrane oxygenation after cardiac surgery be predicted? Ann Thorac Cardiovasc Surg. 2006;12:21-7.

8. Shah SA, Shankar V, Churchwell KB, Taylor MB, Scott BP, Bartilson R, et al. Clinical outcomes of 84 children with congenital heart disease managed with extracorporeal membrane oxygenation after cardiac surgery. ASAIO J. 2005;51: 504-7.

9. Jaggers JJ, Forbess JM, Shah AS, Meliones JN, Kirshbom PM, Miller CE, et al. Extracorporeal membrane oxygenation for infant postcardiotomy support: significance of shunt management. Ann Thorac Surg. 2000;69:1476-83.

10. Kaplan EL, Meier P. Nonparametric estimation from incomplete observations. J Am Stat Assoc. 1958;53:457-81.

11. Katz MH. Multivariable analysis: a practical guide for clinicians. 2nd ed. Cambridge (United Kingdom): Cambridge University Press; 2006. p. 96-136.

12. Vittinghoff E, McCulloch CE. Relaxing the rule of ten events per variable in logistic and Cox regression. Am J Epidemiol. 2007;165:710-8.

13. Harrell FE, Lee KL, Mark DB. Multivariate prognostic models: issues in developing models, evaluating assumptions and adequacy, and measuring and reducing errors. Stat Med. 1996;15:361-87.

14. Baffes TG, Fridman JL, Bicoff JP, Whitehill JL. Extracorporeal circulation for support of palliative cardiac surgery in infants. Ann Thorac Surg. 1970;10:354-63.

15. De Angeli S, Paccagnella A, Mordacchini M, Frugoni C, Zanardo G, Turolla L, et al. The effects of prolonged cardiopulmonary bypass on cell-mediated immunity. Thorac Cardiovasc Surg. 1994;42:14-20.

16. Markewitz A, Faist E, Lang S, Hültner L, Weinhold C, Reichart B. An imbalance in T-helper cell subsets alters immune response after cardiac surgery. Eur J Cardiothorac Surg. 1996;10:61-7.

17. Hadley JS, Wang JE, Michaels LC, Dempsey CM, Foster SJ, Thiemermann C, et al. Alterations in inflammatory capacity and TLR expression on monocytes and neutrophils after cardiopulmonary bypass. Shock. 2007;27:466-73.

18. Tanzi MC. Bioactive technologies for hemocompatibility. Expert Rev Med Dev. 2005;2:473-92.

19. Deptula J, Glogowski K, Merrigan K, Hanson K, Felix D, Hammel J, et al. Evaluation of biocompatible cardiopulmonary bypass circuit use during pediatric open heart surgery. J Extra Corpor Technol. 2006;38:22-6.

20. Wendel HP, Ziemer G. Coating-techniques to improve the hemocompatibility of artificial devices used for extracorporeal circulation. Eur J Cardiothorac Surg. 1999; 16:342-50.

21. Valdés Xenia S. Risk of blood transfusion in cardiac surgery. Arch Cardiol Mex. 2006;76(Suppl. 2):S86-91.

22. Lequier L, Joffe AR, Robertson CM, Dinu IA, Wongswadiwat Y, Anton NR, et al. Western Canadian Complex Pediatric Therapies Program Follow-up Group. Two-year survival, mental, and motor outcomes after cardiac extracorporeal life support at less than five years of age. J Thorac Cardiovasc Surg. 2008;136:976-83.

23. Montgomery VL, Strotman JM, Ross MP. Impact of multiple organ system dysfunction and nosocomial infections on survival of children treated with extracorporeal membrane oxygenation after heart surgery. Crit Care Med. 2000;28: 526-31.

24. Székely A, Cserép Z, Sápi E, Breuer T, Nagy CA, Vargha P, et al. Risks and predictors of blood transfusion in pediatric patients undergoing open heart operations. Ann Thorac Surg. 2009;87:187-97.

25. Terry B, Gunst G, Melchior R, Wolfe D, Feocco N, Graham S, et al. A description of a prototype miniature extracorporeal membrane oxygenation circuit using current technologies in a sheep model. J Extra Corpor Technol. 2005;37: 315-7. 


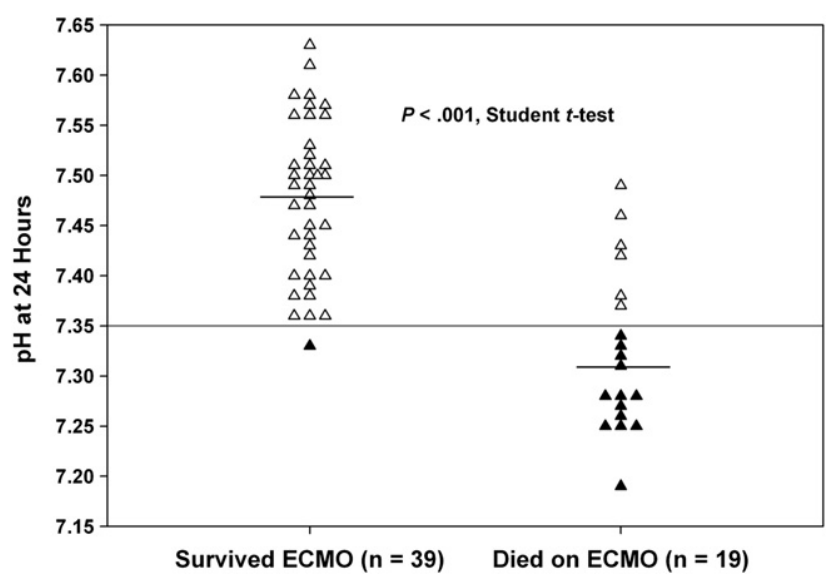

FIGURE E1. Scatter plot showing the actual $\mathrm{pH}$ values at 24 hours for each patient segregated by survival or death on ECMO. The mean $\mathrm{pH}$ was 7.48 for survivors and 7.31 for nonsurvivors $(P<.001)$ as shown by horizontal lines. The triangles below $\mathrm{pH}$ of 7.35 are denoted in black. $E C M O$, Extracorporeal membrane oxygenation.

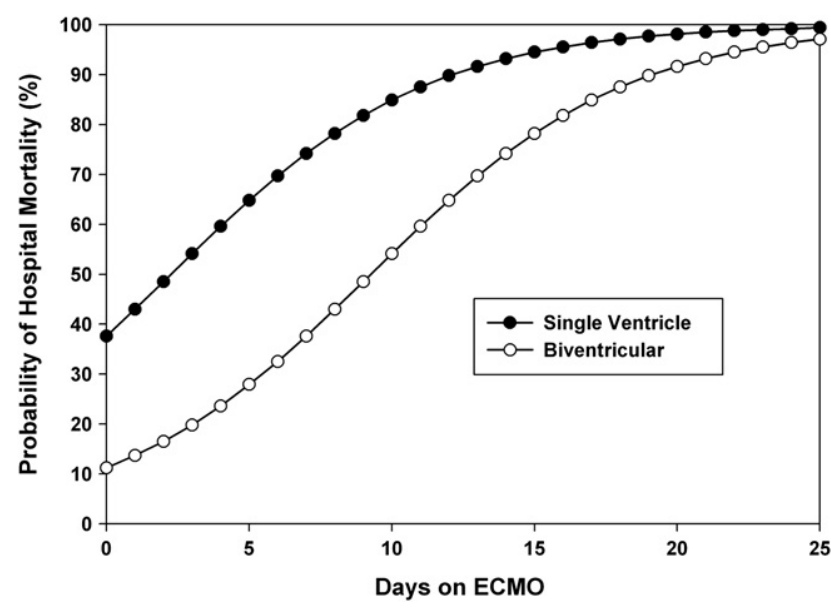

FIGURE E3. Results of multivariate logistic regression analysis illustrating the probability of hospital mortality according to time on ECMO and type of surgical repair. ECMO, Extracorporeal membrane oxygenation.

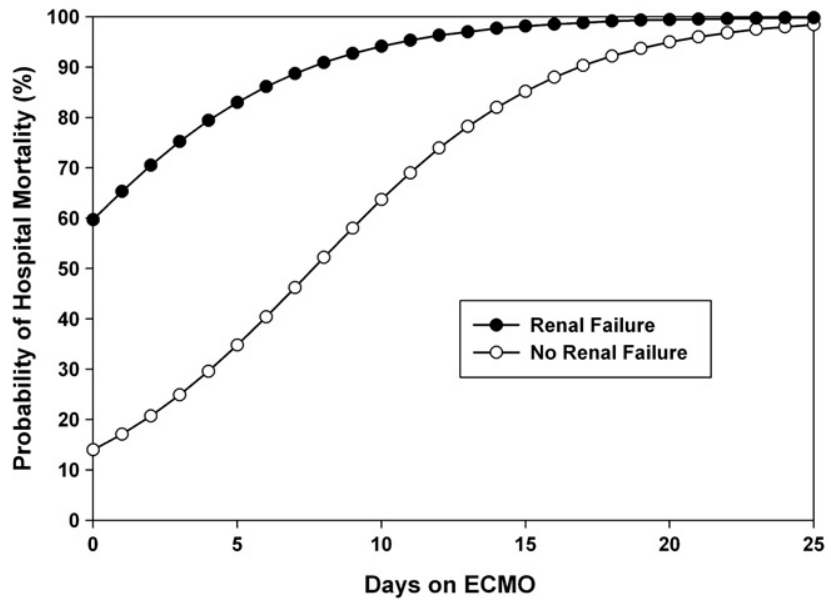

FIGURE E2. Results of multivariate logistic regression analysis illustrating the probability of hospital mortality according to ECMO duration and presence or absence of renal failure. ECMO, Extracorporeal membrane oxygenation. 
TABLE E1. Clinical variables evaluated for influence on outcome

\section{Pre-support variables}

Demographic factors

- Age

- Weight

- Gender

- Ethnicity

Intraoperative features

- Cardiac diagnosis

- CPB time

- Crossclamp time

- Circulatory arrest time

Arterial blood gas values

- $\mathrm{pH}$

- Serum bicarbonate.

- Lactate 1 (4-12 hours before placement on ECMO)

- Lactate 2 (0-4 hours before placement on ECMO)

Inotropes

- Dopamine

- Epinephrine

- Milrinone

- Congenital heart disease type

- Cardiac physiology after surgery

- Indication for ECMO

- Duration of CPR

- Cannulation site

Post-support variables

Arterial blood gas values at 24 hours of support

- $\mathrm{pH}$

- Serum bicarbonate

- Lactate

- Urine output over the first 24 hours of support

Blood product transfusions during suppor.

- Packed RBCs

- Fresh frozen plasma

- Cryoprecipitate

- Platelet

- Mediastinal re-exploration

- Duration of the ECMO

Evidence of organ damage

- Pulmonary

- GI system

- Renal

- Neurologic

- Infectious

- Bleeding.

$C P B$, Cardiopulmonary bypass; $C P R$, cardiopulmonary resuscitation; $R B C s$, red blood cells; GI, gastrointestinal.
TABLE E2. Classification of patients and definition of complications Inotrope score $=$ dopamine + dobutamine + epinephrine

tnorepinephrine $+($ milrinone $\times 15)$ all in $\mu \mathrm{g} \cdot \mathrm{kg}^{-1} \cdot \min ^{-1} \times 100$

Diagnosis of congenital cardiac disease

1. Left-to-right shunt

2. Left-sided obstruction

3. Hypoplastic left heart syndrome

4. Right-sided obstruction

5. Cyanosis with increased pulmonary blood flow

6. Cyanosis with decreased pulmonary blood flow

7. Cyanosis with increased pulmonary congestion

8. Other

Cardiac physiology at the time of deployment of ECMO

1. Single ventricle physiology

2. Biventricular physiology

Indications for ECMO deployment

1. Failure of the patient to come off cardiopulmonary bypass

2. Cardiac arrest in the postoperative period

3. Persistent low cardiac output in the postoperative period

4. Hypoxia

Renal failure: oliguria or anuria with raised creatinine level $(>1.5 \mathrm{mg} / \mathrm{dL})$ requiring hemodialysis

Neurologic complication: intracranial infarct or hemorrhage, evidence of hypoxic insult or brain death

Sepsis: systemic inflammatory response in the presence of infection (suspected or proven) (as defined by International Pediatric Sepsis Consensus Conference, 2005)

Gastrointestinal complication: distended abdomen with absent bowel sounds or abnormal bowel gas pattern or blood in stool

Pulmonary complication: lung collapse, consolidation or any other process like haemorrhage significant enough to interfere with gaseous exchange

Dissiminated intravascular coagulopathy: decreased platelet count that was unresponsive to transfusion, raised activated clotting time in spite of decreasing heparin, elevated prothrombin time and bleeding from surgical sites

TABLE E3. Outcome based on type of repair

\begin{tabular}{lcc}
\hline & $\begin{array}{r}\text { Single ventricle } \\
\text { repair }(\mathbf{n}=\mathbf{3 1})\end{array}$ & $\begin{array}{c}\text { Biventricular } \\
\text { repair }(\mathbf{n}=\mathbf{2 7})\end{array}$ \\
\hline Death on ECMO & $13(42 \%)$ & $6(22 \%)$ \\
Death after weaning from & $10(32 \%)$ & $5(19 \%)$ \\
$\quad$ ECMO and before hospital & & \\
$\quad$ discharge & $8(26 \%)$ & $16(59 \%)$ \\
Discharge from hospital &
\end{tabular}

ECMO, Extracorporeal membrane oxygenation. 